\title{
AKTIVITAS CUSTOMER SERVICE PADA NASABAH DI BANK NAGARI CABANG UTAMA PADANG
}

\author{
Rahmadani, Mariani St.B Tanjung \\ Akademi Keuangan dan Perbankan Padang \\ mstbtanjung@gmail.com
}

\begin{abstract}
The development of the business world today, including the banking sector in the city of Padang in recent years experienced a very rapid progress, this development relates to the sector of national economy, the various facilities provided by the government to create a way or a good atmosphere for the development of business in banking in Indonesia. This is attested by the number of new banks to open branch offices in West Sumatra, especially in Padang. Banking is everything that concerns about banks, institutional, business activities, as well as the manner and process of conducting its business, where its main function is as a collector of funds from the public and to channel back to the community through credits, which aims to support the implementation of development and its results, as well as economic growth in the lives of many people. The number of banks in Indonesia at this time, to make the competition tighter and competing to gain the top rank in society, particularly in the city of Padang. Therefore, a good strategy is needed by each bank in order to increase profits and has good quality. One way the right bank is the role oj Customer Service (CS) in improving customer service to customers in the bank or other institution, because the quality of customer service is the key to success and the basis for building.
\end{abstract}

\section{LATAR BELAKANG}

Perkembangan dunia usaha saat ini termasuk sektor perbankan di kota Padang beberapa tahun belakangan ini mengalami kemajuan yang sangat pesat, perkembangan ini berkait dengan adanya sektor ekonomi nasional, adanya berbagai kemudahan yang diberikan oleh pemerintah dengan menciptakan cara atau suasana yang baik bagi perkembangan usaha di bidang perbankan di Indonesia. Hal ini di buktikan dengan banyaknya bank baru yang membuka 
kantor cabang di Sumatera Barat terutama di Kota Padang.

Perbankan merupakan segala sesuatu yang menyangkut tentang bank, kelembagaan, kegiatan usaha, serta cara dan proses dalam melaksanakan kegiatan usahanya,dimana fungsi utamanya adalah sebagai penghimpun dana dari masyarakat dan menyalurkan kembalikepada masyarakat melalui kredit, yang bertujuan untuk menunjang pelaksanaan pembangunan dan hasil- hasilnya, serta pertumbuhan ekonomi bagi kehidupan rakyat banyak. Banyaknya bank yang ada di Indonesia saat ini, membuat persaingan semakin ketat dan berlomba untuk memperoleh peringkat paling baik dimata masyarakat, khususnya di Kota Padang. Oleh sebab itu, diperlukan strategi yang baik oleh masing-masing bank guna meningkatkan laba dan memiliki kualitas yang baik. Salah satu cara bank yang tepat adalah adanya Peranan Customer Service (CS) dalam meningkatkan pelayanan pelanggan terhadap nasabah di bank atau instansi lain , karena pelayanan pelanggan yang bermutu merupakan kunci sukses dan dasar untuk membangun keberhasilan di suatu perusahaan.

Adapun yang menjadi permasalahan yang akan penulis bahas dalam penelitian ini yaitu : "Bagaimana Peranan Customer Service dalam memberikan pelayanan terhadap nasabah di Bank Nagari Cabang Utama Padang"?

\section{LANDASAN TEORI}

\section{Pengertian Bank}

Menurut Undang-Undang Pasal 1 ayat 2 Undang-Undang No. 10 Tahun 1998 tentang perubahan Undang-Undang Republik Indonesi No. 7 tahun 1992 tentang perbankan : "Bank adalah badan usaha yang menghimpun dana dari masyarakat dalam bentuk simpanan dan menyalurkannya kembali kepada masyarakat dalam bentuk kredit dan atau bentuk- bentuk lainnya dalam rangka meningkatkan taraf hidup rakyat banyak."

Menurut Pasal 5 ayat 1 Undang-Undang No. 10 tahun 1998 yang merupakan perubahan Undang-Undang No. 7 tahun 1992 tentang Perbankan, membagi bank dalam 2 jenis yaitu :

1. Bank Umum

Bank yang melaksanakan kegiatan usaha secara konvensional dan atau berdasarkan prinsip syariah yang dalam kegiatannya memberikan jasa dalam lalu lintas pembayaran.

2. Bank Perkreditan Rakyat

Bank yang melaksanakan kegiatan usahanya secara konvensional atau atau berdasarkan prinsip syariah yang dalam kegiatannya tidak memberikan jasa dalam lalu lintas pembayaran.

Berdasarkan pendapat diatas, maka dapat ditarik kesimpulan, Bank adalah lembaga keuangan yang usaha pokoknya memberikan kredit dan jasajasa dalam lalu lintas pembayaran dan peredaran uang. 


\section{Tujuan Bank}

Berdasarkan Undang- Undang No. 10 tahun 1998 tentang perubahan Undang- Undang Republik Indonesia No. 7 tahun 1992 tentang perbankan, Perbankan Indonesia dalam melakukan usahanya berasaskan demokrasi ekonomi dengan prinsip kehati-hatian. Demokrasi ekonomi itu sendiri dilaksanakan berdasarkan Pancasila dan Undang-Undang 1945.

Berdasarkan asas yang diatas, maka tujuan perbankan Indonesia adalah menunjang pelaksanaan pembangunan nasional dalam rangka meningkatkan pemerataan pembangunan dan hasil-hasilnya, pertumbuhan ekonomi, dan stabilitas nasional ke arah peningkatan kesejahteraan rakyat banyak.

\section{Fungsi Bank}

Fungsi utama bank adalah menghimpun dana dari masyarakat dan menyalurkannya kembali kepada masyarakat untk berbagai tujuan atau sebagai financial intermediary.

\section{Jenis Bank}

\section{a. Bank Umum}

Bank umum adalah bank yang melaksanakan kegiatan usaha secara konvensional dan atau berdasarkan prinsip syariah yang dalam kegiatannya memberikan jasa lalu lintar pembayaran. Sifat jasa yang diberikan adalah umum, dalam arti dapata memberikan seluruh jasa perbankan yang ada. Begitu juga dengan wilayah operasinya dapat dilakukan diseluruh wilayah. Bank umum disebut jugabank komersil (commercial bank).

b. Bank Perkreditan Rakyat (BPR)

Bank perkreditan Rakyat ( BPR ) adalah bank yang melaksakan kegiatan usaha secara konvensional atau berdasarkan prinsip syariah yang dalam kegiatannya tidak memberikan jasa dalam lalu lintas pembayaran. Artinya disini kegiatan BPR jauh lebih sempit jika dibandingkan dengan kegiatan bank umum.

\section{Pengertian Customer Service}

Pengertian Customer Service secara umum adalah setiap kegiatan yang diperuntukan atau ditujukan untuk memberikan kepuasan kepada nasabah melalui pelayanan yang dapat memenuhi keinginan dan kebutuhan nasabah.

\section{Tugas seorang Customer Service}

Dalam praktiknya fungsi Customer Service adalah sebagai resepsionis, sebagai deskman, sebagai salesman, sebagai Customer Relation Officer, sebagai Komunikator.

\section{Sikap dan Perilaku Seorang Customer Service}

Sikap dan perilaku merupakan bagian terpenting dalam perbankan. Adanya sikap dan perilaku yang harus di jalankan oleh setiap pegawai bank adalah jujur dalam bertindak dan bersikap, rajin, tepat waktu ,dan tidak pemalas, selalu murah senyum, lemah lembut dan ramah tamah, sopan santun tutur sapa dan hormat, bertanggung jawab dan suka menolong nasabah. 


\section{METODE PENELITIAN}

Jenis penelitian yang digunakan peneliti dalam penelitian ini yaitu deskriptif kuantitatif, penelitian ini dilakukan di PT. Bank Nagari Cabang Utama Padang, Data yang digunakan adalah data sekunder.

Dalam pengumpulan data dan bahan untuk melakukan penelitian ini, digunakan metode- metode pengumpulan data sebagai berikut :

1. Metode pengumpulan data

a. Studi lapangan

Pada penelitian ini dilakukan dengan cara melakukan pengamatan langsung dan melakukan wawancara dengan pihak-pihak yang terkait.

b. Studi Kepustakaan

Penelitian ini dilakukan dengan mengumpulkan data dan menggunakan teori-teori yang berkaitan dengan masalah- masalah yang akan di bahas, yang di peroleh dari literature yang ada berupa buku-buku yang berkaitan dengan masalah.

\section{HASIL DAN PEMBAHASAN}

1. Peranan Customer Service dalam Meningkatkan Pelayanan Terhadap Nasabah. Peranan seorang Customer Service dalam meningkatkan pelayanan terhadap nasabah pada PT. Bank Nagari Cabang Utama Padang merupakan kunci sukses dan dasar untuk membangun keberhasilan bank tersebut. Oleh karena itu, segala kegiatan harus berjalan dengan baik dan bermutu demi terciptanya kepuasan nasabah. Karena nasabah yang merasa mendapatkan kepuasan akan kembali lagi mendatangi bank tersebut dan membeli produk lain yang ditawarkan oleh bank serta akan berbagi cerita dengan rekan yang lainnya dan memberikan fasilitas yang nyaman seperti AC dan pewangi ruangan agar nasabah lebih nyaman berada dalam ruangan pada saat gantri.

2. Fungsi Customer Service Pada Bank Perkreditan Rakyat Jorong Kampung Tangah Pariaman. Dalam praktiknya fungsi Customer Service adalah sebagai resepsionis, sebagai deskman, sebagai salesman, sebagai customer relation officer, sebagai komunikator.

3. Aktivitas Pembukaan Rekening Oleh Customer Service

Adapun aktivitas yang dilakukan oleh Customer service di Bank Nagari

Cabang Utama Padang adalah sebagai berikut :

1. Pembukuan rekening dan penutupan rekening.

a. Rekening Giro.

b. Rekening Tabungan.

c. Deposito Berjangka.

2. Informasi saldo rekening giro dan tabungan.

3. Pemesanan dan mencetak buku cek atau bilyet giro dan tabungan.

4. Penyerahaan atau pengiriman buku cek atau bilyet giro.

5. Aktivitas lainnya non-tunai. 


\section{KESIMPULAN DAN SARAN}

1. Kesimpulan

Berdasarkan uraian dan pembahasan yang telah dikemukakan dalam bab sebelumnya, maka dapat diambil kesimpulan sebagai berikut :

1) Customer Service adalah seorang komunikator dengan cara memberikan segala informasi dan kemudahan- kemudahan kepada nasabah dan juga sebagai tempat menampung keluhan, keberatan, atau konsultasi antara kepentingan bank dengan kepentingan nasabah.

2) Customer Service memegang peranan sangat penting dalam memberikan pelayanan dan dituntut untuk selalu berhubungan dengan nasabah dan menjaga hubungan itu tetap baik. Hal ini tentu saja harus dilakukan karena menjaga hubungan yang baik dengan nasabah juga berarti menjaga image bank agar citra bank dapat terus meningkat di mata nasabah.

3) Bahwasanya peran Customer Service dalam meningkatkan loyalitas nasabah sangatlah penting melalui pelayanan yang diberikan oleh bagian Customer Service. Pelayanan Customer Service berupa memberikan kemudahan kepada para nasabah.

2. Saran

Saran yang dapat diberikan penulis sehubungan dengan uraian-uraian sebelumnya adalah sebagai berikut :

1) Dalam memberikan pelayanan, Customer Service harus ramah dan selalu dituntut agar dapat memuaskan nasabah tanpa melanggar harga diri atau etika.

2) Apabila ada masalah atau pengaduan dari nasabah tentang produk dan jasa yang ditawarkan, agar Customer Service dengan sabar mendengarkan segala keluhan yang dihadapi nasabah.

3) Kinerja Customer Service terus ditingkatkan, karena peranan Customer Service sangat penting dan merupakan tulang punggung kegiatan operasional. Dalam dunia Perbankan sebaiknya pihak bank perlu memberikan ketrampilan yang lebih bagi Customer Service. Dalam hal ini berupa training tambahan dengan dukungan sarana dan prasarana yang memadai. Dengan training tersebut diharapkan bisa memberikan kepuasan pada nasabah dengan memberikan pelayanan yang terbaik.

\section{DAFTAR PUSTAKA}

Budisantoso, Totok dan Sigit Triandaru. 2000. Bank dan Lembaga Keuangan Lainnya, Jakarta.

Fernandes, Y. D., \& Marlius, D. (2018). Peranan Customer Service Dalam Meningkatkan Pelayanan Kepada Nasabah Pada PT. Bank Pembangunan Daerah Sumatera Barat Cabang Utama Padang. https://doi.org/10.31227/osf.io/wrh3p

Kasmir, SE.,MM, 2007 Dasar-dasar Perbankan, PT. Raja Grafindo Persada,

Martini, William B, 2004, Quality Customer Service, Penerbit PPM, Jakarta.

Mirawati \& Fernos, J. (2019). Peranan Customer Service Dalam Meningkatkan Pelayanan Terhadap Nasabah Pada Bank Nagari Cabang Siteba Padang. 
https://doi.org/10.31227/osf.io/cq458

Putra, A. M., \& Fernos, J. (2019). Pelaksanaan Pelayanan Prima Terhadap Kepercayaan Nasabah Di PT. Bank Perkreditan Rakyat Jorong Kampung Tangah Pariaman. https://doi.org/10.31227/osf.io/c3fy4

Sunarto, 2006, Customer Service, Penerbit Amus, Yogyakarta.

Situmorong, Syafrizal Helmi, 2008, Perencanaan dan Pengembangan Bisnis Penerbit USU Press, Medan.

Undang-undang Perbankan Nomor 10 Tahun 1998 Tentang Perubahan

Undang- Undang Nomor 7 Tahun 1992 Tentang Perbankan. Jakarta: Sinar Grafika.

Yuvendri, R., \& Susanto, R. (2019). Meningkatkan Mutu Pelayanan Dalam Usaha Menghimpun Dana Masyarakat (Tabungan) Pada PT. Bank Perkreditan Rakyat Prima Mulia Anugrah Cabang Padang. https://doi.org/10.31219/osf.io/6prcd

Widayati, R. (2019). Promotional Activities And Services Bank Nagari Kambang Increase In Customer. https://doi.org/10.17605/OSF.IO/MYAVT

Widodo, B. H., \& Susanti, F. (2019). Pengaruh Human Relation (Hubungan Antar Manusia), Lingkungan kerja Terhadap Etos Kerja karyawan (Studi Kasus Pada PT. Pelindo Teluk Bayur Padang ). https://doi.org/10.31227/osf.io/dxm8a 